\title{
Development of Automated Approaches for HydropowerPotential Estimations and Prospective Hydropower Plants Siting
}

\author{
Nikolay Arefiev ${ }^{1}$ Olga Nikonova1, Nikolay Badenko², Timofey Ivanov², \\ Vyacheslav Oleshko ${ }^{2}$ \\ ${ }^{1}$ Saint-Petersburg Polytechnical University, Civil Engineering Institute, \\ Address: Polytechnicheskaya str., 29, Saint-Petersburg, 195251, Russia; \\ ${ }^{2}$ Nikolay Badenko, Timofey Ivanov, Vyacheslav Oleshko, JSC VNIIG, laboratory of \\ Geographic Information Systems and Technologies \\ Address: Gjatskaya str., 21, Saint-Petersburg, 195220, Russia
}

\begin{abstract}
Hydropower potential studies usually include estimation of hydropower resources and creating propositions for hydropower development on study area. The current paper describes authors' study, dedicated to development of methodological approaches and software designed for solving problems stated above. Process automation is achieved by using geographic information systems (GIS) and additional programs (Python language was used).

Hydropower potential estimation is the key element for understanding future prospects of hydropower development within the study area. The latest large-scale hydropower potential studies of Russian territories were held in 1940-1980. In those times, such researches were carried out almost without any automation, so calculation process was time-consuming. As a result, only hydropower potential of large and several medium-sized rivers was estimated; hydropower potential assessments of small rivers were conducted only using approximate approach.

Nowadays, implementation of technologies and software products, such as geographic information systems, contributes to development of methodologies, which can be used to automate business-processes in different scientific disciplines, including processes of hydropower potential estimation and prospective hydropower plants siting. In comparison with former studies, GIS allow to reduce labor work significantly and to perform analysis of large study areas and large number of streams (including small rivers) in relatively short time using up-to-date topographical, hydrological and hydrographical information.

Authors have developed and tested methodological approach and GIS-tools for automated hydropower potential estimation. Re-estimation of hydropower potential was fulfilled by the authors for the most part of Russia. The data for more than 10000 river's was compared to the results of prior studies (data, such as river basin area, annual river flow, hydropower potential). The gross hydropower capacity of rivers and gross hydropower potential were estimated as $350 \mathrm{GW}$ and $3,07 * 103 \mathrm{TWh}$ respectively.

The next step in hydropower potential studies is prospective hydropower plants siting. Authors developed methodological approach and GIS-tools to automate this process. The GIS-tools provide comparison of site alternatives based on their hydropower parameters; transport, infrastructure, electricity network proximity; topographic situation and other factors affecting site suitability. Algorithm of automation and results of the search siting are presented.
\end{abstract}

Keywords: Geographic information systems, Hydropower potential, Hydropower plants siting.

\section{INTRODUCTION}

\section{A. Relevance of the research}

Large-scale studies of Russian rivers hydropower potential are currently conducted in order to identify locations of prospective small hydropower plants [1], [2].

Previous large-scale studies of hydropower potential of large and medium-sized rivers in Russia were conducted in 1940-1980. These studies were held by Grigoriev S.V. (1946, [3]), Voznesensky A.N. (1967, [4]), Feldman B.N. (1985, [5]).

Due to insufficient amount of annual rivers flow data (especially in the eastern regions of the country) and poor precision of topographic data, assessment of hydropower potential in these studies was approximate and it was performed only for large and medium-sized rivers [4].

In addition, due to complexity of these researches and a large amount of rivers studied (for example,

ISSN 1691-5402 
4702 rivers in study [4]), estimations of hydropower potential performed in 1940-1980 have required a lot of time and labor.

Usage of modern computer technologies, such as geographic information systems (GIS), allows building tools which provide partial automation of hydropower potential calculations. However, analyzing of recent researches and developing methodology of automated hydropower potential calculations was needed to build these tools.

Present paper describes approaches of automated hydropower calculations, based on ESRI ArcGIS Desktop and modules for interactive data processing (GIS server ESRI technologies), developed and implemented by the authors. Comparisons of catchment areas, flow rates and gross hydropower potential values obtained in this research and the results of past years studies are given.

Presented approaches allow partially automated calculation of Russian rivers hydropower potential using updated hydrological data and relevant digital terrain models.

\section{B. Analysis of other GIS-based studies of hydropower potential}

Estimation of hydropower potential using GIS was lately performed for a set of countries (USA, France, Italy, Norway, Canada, Scotland and others) examples are shown in $[6,7,8,9,10]$. Brief review of these researches was described in [6]. Also, paper [6] overviews some GIS-based tools for hydropower assessments.

The main difference between the GIS-based tools described in [6] is in the initial data which was used for hydropower assessment. The key initial data that is necessary for hydropower potential calculations includes hydrographic data, terrain data and hydrological data (in particular, mean annual flow rates). The studies mentioned in [6] use GIS-layers for hydrographic data, digital elevation models (DEM) as terrain data and annual river runoff or annual river runoff module (liters per sec. / sq. km.) values for flow rates calculation.

Paper [7] describes methodology of calculating gross, available and economic potential of the United States of America. National Hydrography Dataset [11] (synthetic rivers network for territory of the entire country) was used as hydrographic data, SRTM [12] was used as DEM and runoff data was derived from precipitation data.

\section{Purpose of the research}

The main purpose of this study was to develop and implement methodology and GIS-based tools to automate the calculation of the hydropower potential of rivers and stream reaches.

Based on the analysis of previous studies authors have performed the following tasks:
1. Methodology
of partially
automated

hydropower calculation was proposed and requirements for initial data (terrain, hydrographic and hydrological) for calculation were described;

2. Terrain, hydrographic and hydrologic data was gathered and systemized;

3. ArcGIS Desktop based tools for calculating hydropower potential were developed;

4. Several Esri GIS-server technologies based applications were developed for automating calculations, for verification and presenting of the results;

5. Proposed approaches were implemented on a set of hydrological units in Russia, the results for a selected hydrological unit (Ket river watershed, basin of upper $\mathrm{Ob}$ ) are presented in the paper;

6. Results of calculations (watershed areas, flow rates, gross potential values) were compared to the results of prior studies.

\section{METHODOLOGY DESCRIPTION AND REQUIREMENTS FOR INITIAL DATA}

\section{A. Proposed approach for dividing territory into} calculating zones

Hydropower potential estimations are usually performed for large areas, so there is a need in organizing data using hierarchical structures. Territory of Russian Federation is divided into hydrological units based on rivers' watersheds.

In present research basin-landscape approach was used for calculating of hydropower potential. The advantage of this approach is that boundaries of hydrological units are coincident with natural watersheds, which is necessary for delineating catchments inside the study area.

Currently classification of water use zoning in Russia includes 4 levels of classification of hydrological units: regions, basins, sub-basins and the so called water management areas (Figure 1). Water management area is selected as the smallest area for calculation of hydropower potential.

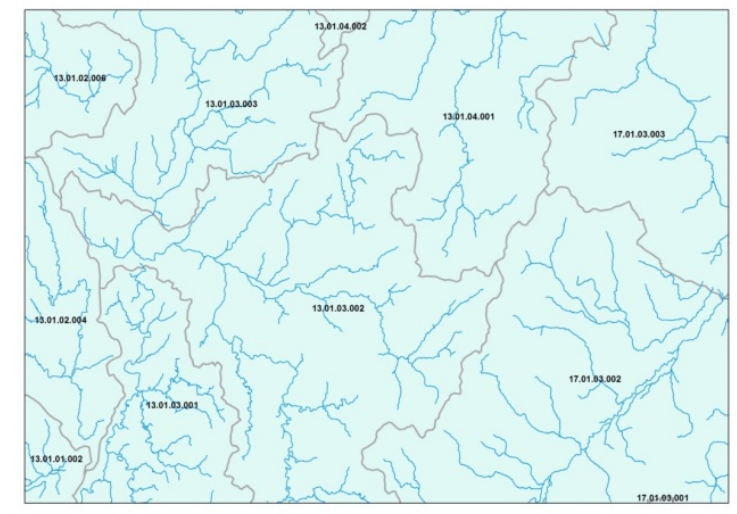

Fig. 1. Example of Russian water use zoning map (zones with identifiers) 


\section{B. Categories of hydropower potential}

According to [4] there are 3 categories of hydropower potential:

Gross hydropower potential is the full theoretical sum of water flow energy.

Gross hydropower potential of a river can be calculated by summing potentials of its stream reaches:

$$
\mathrm{P}=\sum_{i=1}^{\mathrm{n}} N i * t=\sum_{\mathrm{i}=1}^{\mathrm{n}}\left[g *\left(\frac{Q_{1 \mathrm{i}}+Q_{2 \mathrm{i}}}{2}\right) * \mathrm{H}_{\mathrm{i}}\right] * t
$$

$\mathrm{P}$ - gross hydropower potential, $\mathrm{kWh}$

$\mathrm{Ni}$ - gross capacity of a stream reach, $\mathrm{kW}$

$\mathrm{i}$ - number of stream reach

$\mathrm{g}-$ the acceleration of gravity, $\mathrm{m} / \mathrm{s}^{2}$

$Q_{1 \mathrm{i}}$ - flow rate in beginning point of stream reach, $\mathrm{m}^{3} / \mathrm{s}$

$Q_{2 \mathrm{i}}$ - flow rate in ending point of stream reach, $\mathrm{m}^{3} / \mathrm{s}$

$\mathrm{H}$ - elevation difference on stream reach, $\mathrm{m}$

$\mathrm{t}=8760$ hours - the number of hours per year

In this study the same approach as in [4] was used:

streams are divided by the sections (stream reaches) between the tributaries where the flow rate significantly increases.

Technical hydropower potential is a part of theoretical hydropower potential that can be technically used.

In most cases estimation of technical potential is based on analysis of empirical data of the studied rivers [4]. According to [5], rivers in Russia may be classified by annual mean power $(\mathrm{N})$, which can be obtained from annual mean flow rate of stream reach:

$\mathrm{N}<2 \mathrm{MW}$ - first group (Theoretical usage coefficient is set as 0,17 );

$2 \mathrm{MW}<\mathrm{N}<100 \mathrm{MW}-$ second group $\left(K_{i}=0,35\right)$;

$\mathrm{N}>100 \mathrm{MW}$ - third group.

Theoretical usage coefficient for the third group in the current study was set to 0,$4 ; 0,5 ; 0,6$ for rivers with the slope of less than $1,0 \mathrm{~m} / 1,0 \mathrm{~km} ; 1,0-2,5 \mathrm{~m} / 1 \mathrm{~km}$; over 2,5 / 1,0 km respectively.

Economical hydropower potential is a part of technical hydropower potential that is feasible for usage. This study doesn't cover economical potential estimation. Traditionally estimation of economical potential is a complex work due to the necessity of analyzing many factors affecting the feasibility studies of HPP sites [4, 5, 13, 16].

In many studies researchers also estimate available hydropower potential, which is the gross hydropower potential for all the river sections (stream reaches) that are not situated in excluded areas [7]. Usually the stream reaches, where flooding territories is prohibited or where the potential is already used are excluded.

In the current study the following territories are excluded: ecologically protected areas; reservoir territories; territories that are classified as improper for creating HPPs due to geotechnical conditions.

C. Initial Data for gross hydropower potential calculation

In the current study authors used the following data to calculate gross hydropower potential:

1. Russian water register database [14]

Russian water register is a systemized information catalog of water objects, situated in Russia. The register holds information about the river basin areas, lengths, identifiers of water management areas and etc.

2. Terrain data

The study uses digital elevation models (DEM) as the terrain data. Authors used the following DEMs in the current study: SRTM; DEM based on digital maps (scale 1:100000).

3. River's flow rate.

For estimating hydropower potential using (1) a river flow rates at every tributary inflow site are needed. Two possibilities of flow rate calculation were taken into account:

- Usage of 1976's annual river runoff module (q, liters per sec. / sq. km.) map.

- Creating an up-to-date annual river runoff module (q, liters per sec. / sq. km.) map.

D. Algorithm for theoretical hydropower potential calculation

Algorithm implemented for gross hydropower potential calculation is as follows (Figure 2). 


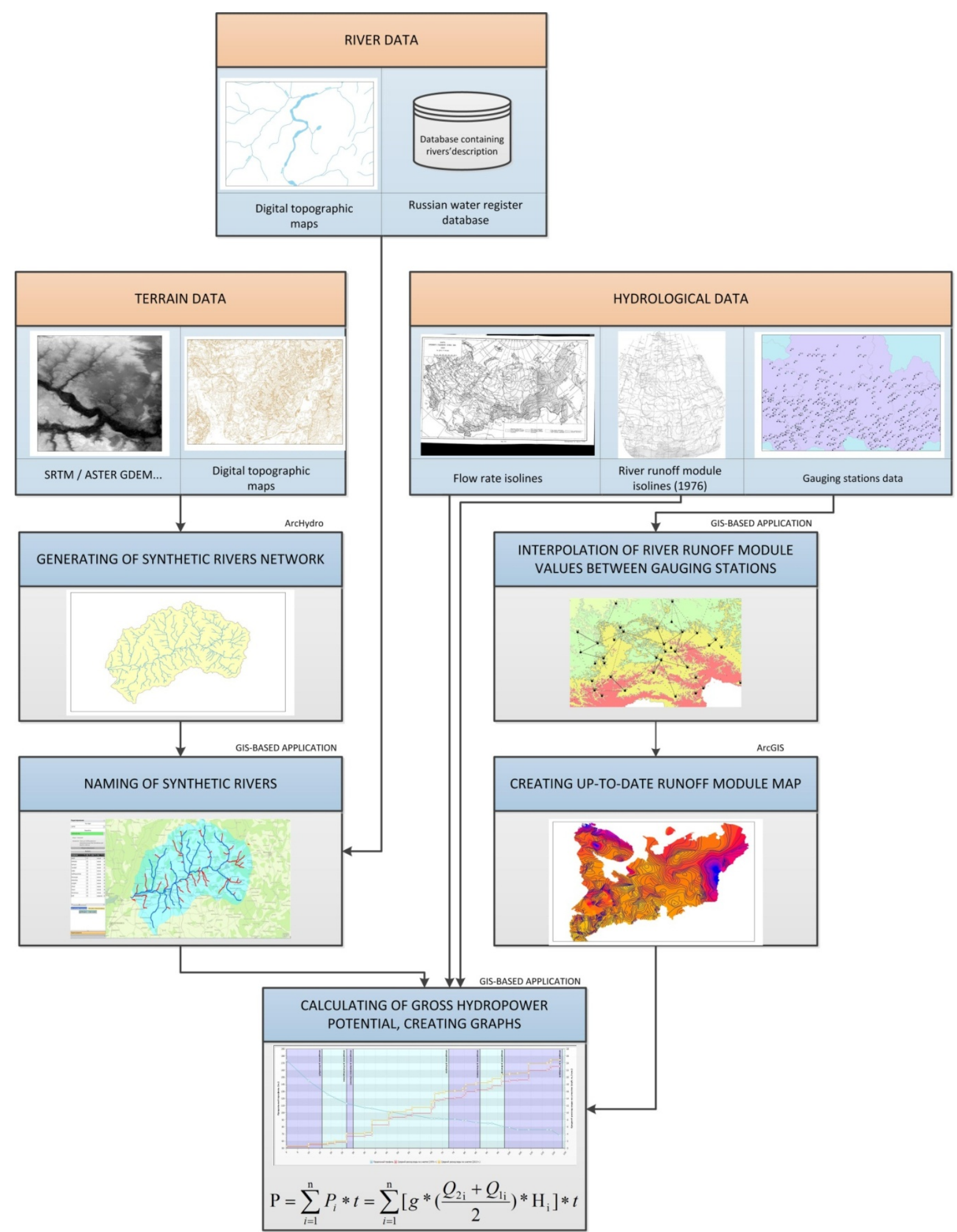

Fig. 2. Algorithm for gross hydropower potential calculating

1. Synthetic river creation. The latest studies of hydropower potential estimation deal with synthetic rivers, which are mathematical models of river flow networks, calculated from the terrain data using a set of algorithms.
ArcHydro Toolset for ArcGIS Desktop was used and extended for the needs of this study.

Comparison of synthetic rivers and rivers obtained from digital maps showed that the tributary's sites match well, but the source 
of real rivers and synthetic rivers don't match. This is due to the fact, that finding a source of a real river always needs a complex study. At the same time source of a synthetic river placement (as well as synthetic rivers network density) depends on a set of thresholds in the algorithm [15].

2. In present study the partially automated algorithm for synthetic rivers naming was created to have the possibility for verifying current study results with the results obtained in previous researches. GIS-based application was created to match synthetic stream reaches with GIS-layers containing rivers. When all stream reaches which belong to the same river are selected, the name of this river is automatically assigned to them. Besides this, length and watershed area taken from Russian water register database are assigned to synthetic rivers.

3. For synthetic rivers' named stream reaches gross hydropower potential can be obtained using formula (1), where:

$$
\mathrm{H}_{\mathrm{i}}=\mathrm{H}_{2 \mathrm{i}}-\mathrm{H}_{1 \mathrm{i}}
$$

DEM is used to obtain beginning and ending point elevations of stream reach.

$$
\begin{aligned}
& \mathrm{Q}_{1 \mathrm{i}}=\mathrm{q}_{1 \mathrm{i}} * \mathrm{~F}_{1 \mathrm{i}} \\
& \mathrm{Q}_{2 \mathrm{i}}=\mathrm{q}_{2 \mathrm{i}} * \mathrm{~F}_{2 \mathrm{i}}
\end{aligned}
$$

Where:

$\mathrm{Q}$ - annual flow rate, $\mathrm{m}^{3} / \mathrm{s}$;

$\mathrm{q}$ - the average annual river runoff module inside a watershed area, $1 /\left(\mathrm{s} * \mathrm{~km}^{2}\right)$

$\mathrm{F}$ - watershed for a selected site at a river, $\mathrm{km}^{2}$

Runoff module in beginning and ending point of stream reach is a mean value of runoff module raster cells inside respective catchment area.

\section{APPROBATION OF PROPOSED METHODOLOGY FOR CALCULATING THE HYDROPOWER POTENTIAL USING GIS- TECHNOLOGIES}

For approbation of proposed methodology water management area with hydrologic unit code (HUC) 13.01.06.001 was chosen. This water management area belongs to Upper $\mathrm{Ob}$ basin and presents river Ket's watershed. This water management area was chosen because there is a possibility for comparing obtained in current study values of gross hydropower potential for river Ket with results obtained in the previous study [4, p.89]. Also, flow rates and watershed areas for several Ket's tributaries are known.

Approbation of proposed methodology included following steps:

1. Creating synthetic river network (Figure 3)

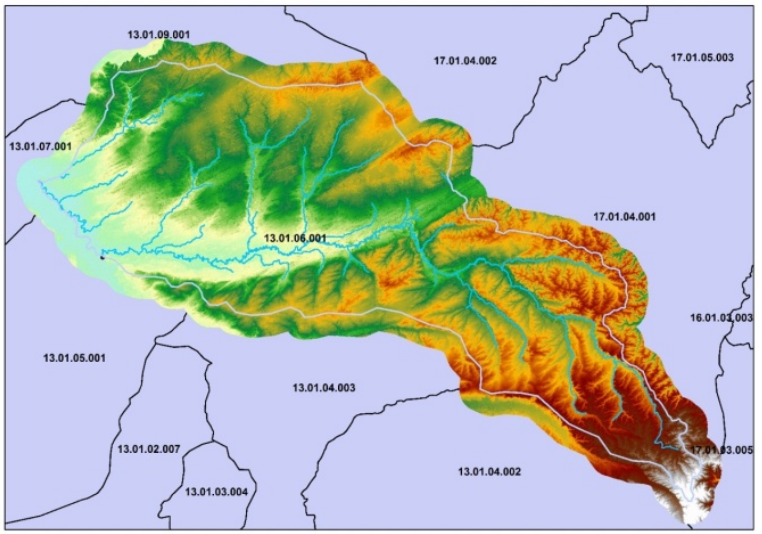

Fig. 3.Synthetic river network created for water management area 13.01.06.001

Naming of synthetic rivers according to digital map GIS-layer for "real" rivers. Real values of lengths and watershed areas were assigned to synthetic rivers using data from Russian water register database (Figure 5). 


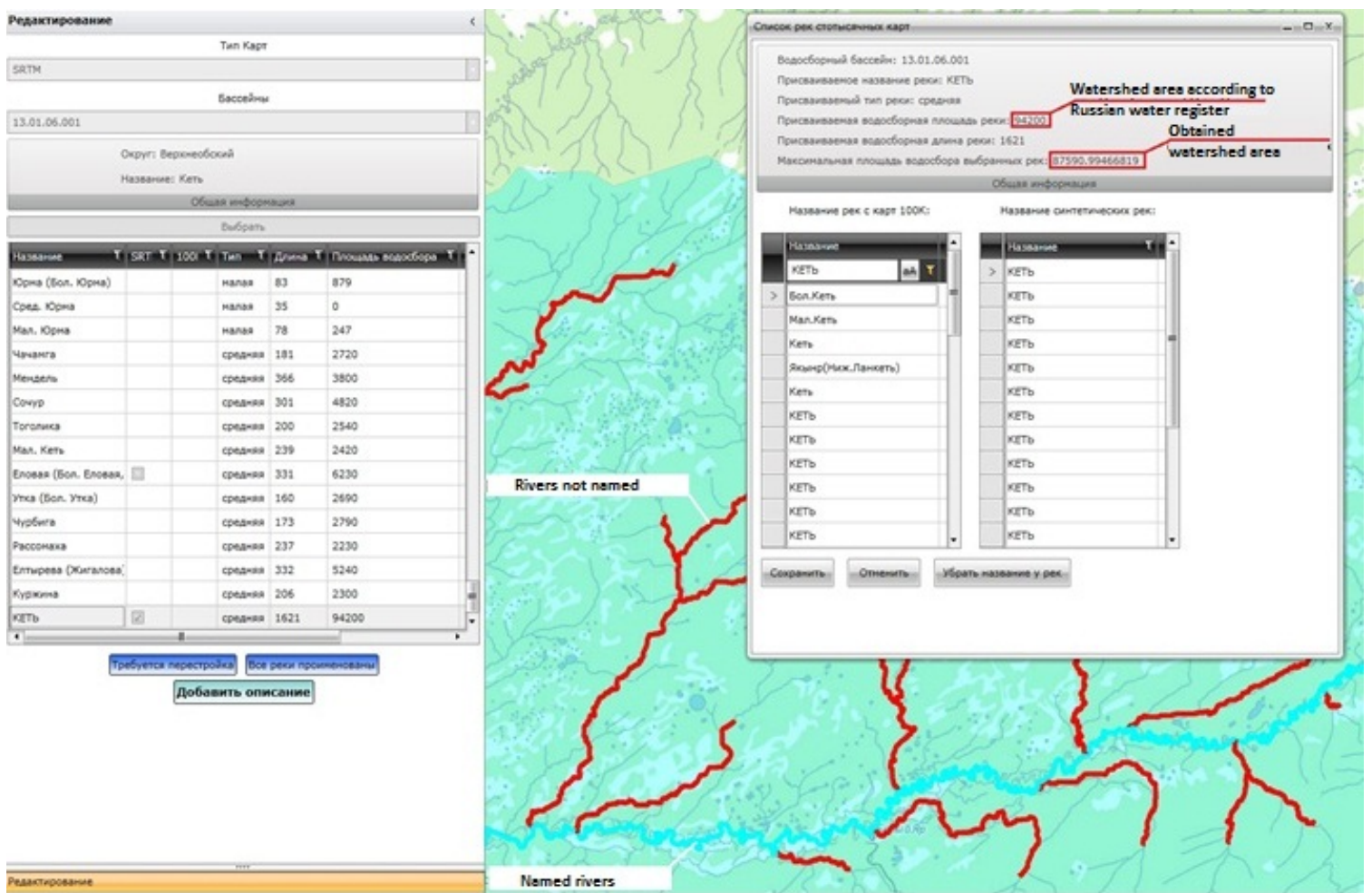

Fig. 4. Naming of synthetic rivers

2. Automated calculation of hydropower potential for all created synthetic rivers was performed.

Calculation results are presented on Figure 7. Process of calculation is rapid: 81 stream reaches were processed in 1,5 minutes (the study area is over 90000 sq.km).

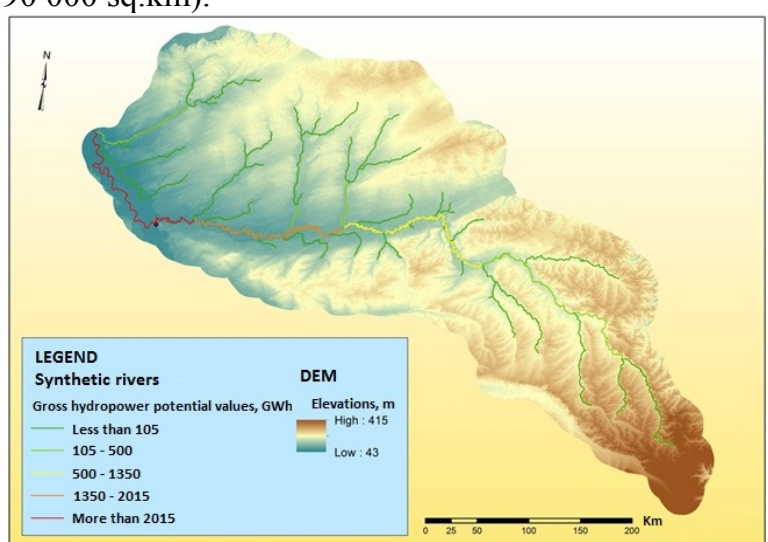

Fig. 5.Hydropower calculation results for water management area 13.01.06.001

Automated creation of graphs presenting longitudinal profile of rivers, increase of flow rate over the river and increase of hydropower potential over the river can be done using the GIS-based application, developed by the authors.
3. There were no excluded zones (ecologically protected areas or territories improper for creating HPPs due to geotechnical conditions) and existing reservoirs inside the study area, used for approbation. Hence, available potential is equal to gross hydropower potential of the rivers.

4. For each stream reach theoretical usage coefficient was calculated automatically and technical hydropower potential was obtained.

5. Verification of obtained results was performed including:

- Verification of watershed areas.

Obtained results were compared with Russian water register data [14] (Table 1).

- Verification of flow rates in pour points.

Verification of obtained based on up-to-date runoff module flow rate values was performed. These values were compared with relevant gauge stations data and collected from prior studies data (Table 2).

- Verification of gross hydropower potential. Gross hydropower potential of river Ket obtained in this study was compared with [4]. Calculation of hydropower potential in [4] was made only for river trunk (river itself); tributaries were not included in calculations. Comparison of the results is shown in Table 3. 
TABLE 1

VERIFICATION OF WATERSHED AREAS

\begin{tabular}{|l|l|l|l|}
\hline River name & Obtained watershed area, sq.km & $\begin{array}{l}\text { Watershed area according to } \\
\text { Russian water register database, } \\
\text { sq.km }\end{array}$ & Discrepancy, \% \\
\hline Orlovka & 9010 & 2,3 \\
\hline Churbiga & 8804 & 2790 & 5,1 \\
\hline Kelma & 2647 & 1390 & 3,1 \\
\hline Sochur & 1347 & 4820 & 5,1 \\
\hline Yelovaya & 5079 & 6230 & 4,0 \\
\hline Ket & 6067 & 94200 & 7,0 \\
\hline
\end{tabular}

TABLE 2

VERIFICATION OF FLOW RATES IN POUR POINTS

\begin{tabular}{|l|l|l|l|l|}
\hline River name & $\begin{array}{l}\text { Obtained flow rate, } \\
\text { cubic meter per } \\
\text { second }\end{array}$ & $\begin{array}{l}\text { Flow rate according to } \\
\text { relevant gauge stations } \\
\text { data, cubic meter per } \\
\text { second }\end{array}$ & $\begin{array}{l}\text { Flow rate according to [4], } \\
\text { second year., cubic meter per } \\
\text { second }\end{array}$ & $\begin{array}{l}\text { Discrepancy of obtained and } \\
\text { relevant flow rates, \% }\end{array}$ \\
\hline Orlovka & 62,0 & 63,5 & - & 2,3 \\
\hline Ket & 572,5 & 560 & 531 & 2,1 \\
\hline
\end{tabular}

TABLE 3

COMPARISON OF GROSS HYDROPOWER POTENTIAL OBTAINED IN CURRENT STUDY AND IN STUDY [4]

\begin{tabular}{|l|l|l|l|}
\hline River name & $\begin{array}{l}\text { Gross hydropower potential } \\
\text { obtained in current study, GWh }\end{array}$ & $\begin{array}{l}\text { Gross hydropower potential } \\
\text { obtained in [4], GWh }\end{array}$ & Discrepancy, \% \\
\hline Ket & 2490 & 2129 & 14,5 \\
\hline
\end{tabular}

Discrepancy in gross hydropower potential obtained in the present study and in [4] is due to updating of hydrological data and using DEM, that can cause some discrepancies in obtaining watershed areas as compared with traditional methods of delineating watersheds.

Also, the methodology used in the current study allows to automatically calculate the hydropower potential for a river itself and for the basin (the gross hydropower potential of a river and its tributaries are summed). Total Ket's river basin hydropower potential was estimated as $3387 \mathrm{GWh}$.

\section{APPLYING PROPOSED METHODOLOGY FOR ESTIMATING HYDROPOWER POTENTIAL OF RIVERS IN RUSSIA}

Authors created synthetic rivers networks for entire territory of Russia and hydropower potential calculations were performed. Density of synthetic rivers networks corresponds to second-third order tributaries. Russian rivers gross hydropower capacity and gross hydropower potential were estimated as $350 \mathrm{GW}$ and $3,07 * 10^{3}$ TWh respectively.

Obtained results subsequently will be used for purposes of small hydropower plants siting. Generalized algorithm of this process is provided in Section 5.

\section{GENERALIZED ALGORITHM FOR} AUTOMATED SEARCH OF FEASIBLE SMALL HYDROPOWER PLANTS SITES

This section includes only brief introduction to the methodology of economical hydropower potential estimation developed by the authors. The detailed methodology description will be presented after the verification of results of automated sites search.

The algorithm of entire process of prospective hydropower plants siting is shown on Fig. 6. 


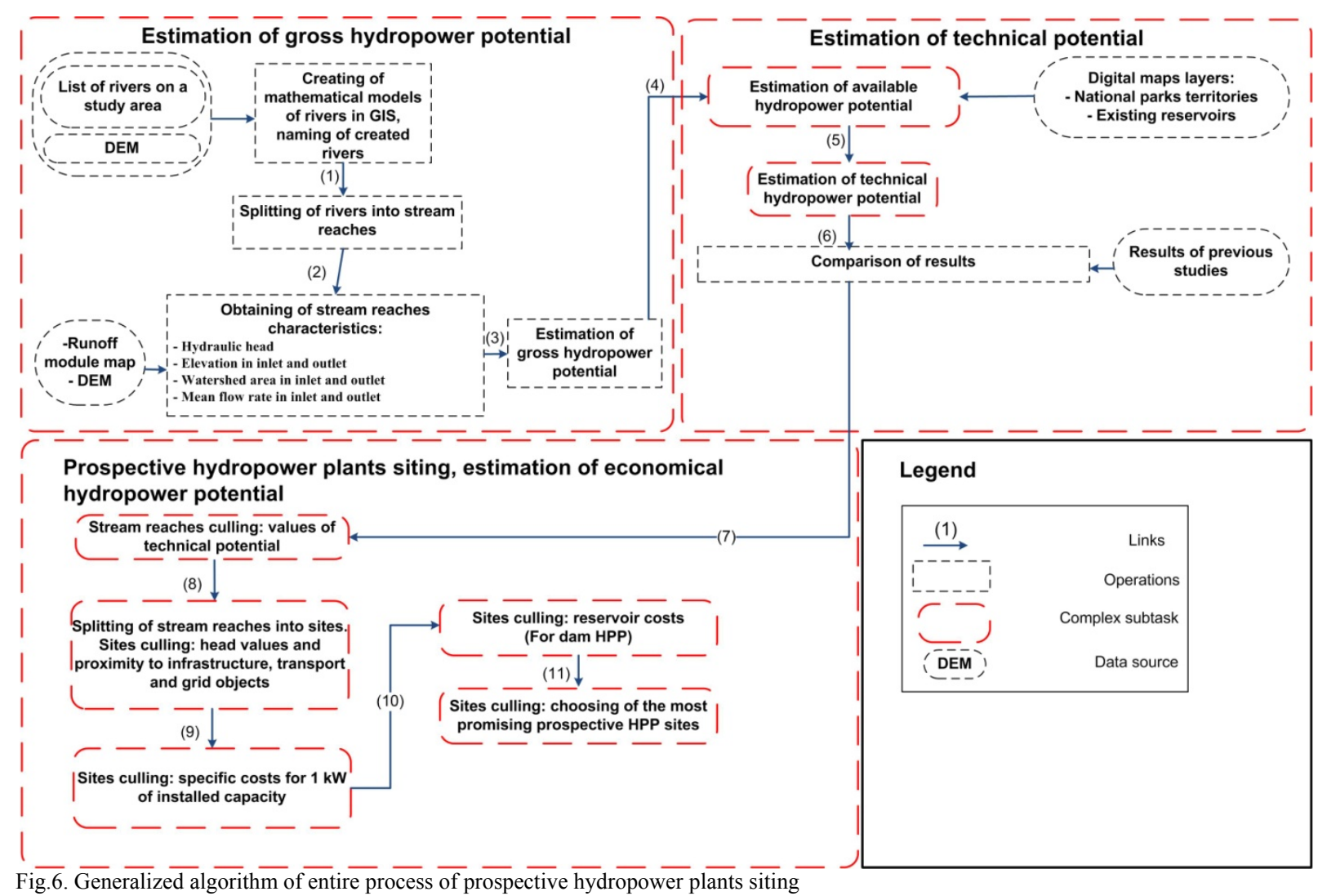

To identify locations for prospective sites, first, stream reaches with low values of technical hydropower potential should be excluded.

After that, every remaining stream reach should be split into sites, and basic technical characteristics (installed capacity, discharge and head) of sites should be calculated.

Algorithm for small hydropower plants siting provides the way to identify suitable locations for dam HPPs and diversion HPPs. In case of dam HPP siting, at every site a list of HPP variants with different installed capacity should be analyzed. For each variant, the HPP head might be obtained using equation:

$$
\mathrm{H}=\frac{\mathrm{N}}{8 \mathrm{Q}}
$$

Where:

$\mathrm{H}$ - HPP head, m;

$\mathrm{N}$ - installed capacity, $\mathrm{kW}$;

$\mathrm{Q}$ - HPP discharge, $\mathrm{m} 3 / \mathrm{s}$.

In case of diversion HPP, a penstock should be drawn from every site to every site inside the current stream reach. Elevation difference between inlet and outlet of penstock is the head of HPP, so, the installed capacity can be calculated using (6).
After obtaining basic HPP technical characteristics, a list of criteria can be used to exclude sites not matching the criteria:

- If obtained value of HPP head and discharge does not match the range of head and discharge values for HPP equipment, this site should be excluded.

- Proximity to infrastructure, transport and power grid objects affects site suitability. If site is located too far from settlements, roads, power grid, etc., this site should be excluded.

- Specific costs for $1 \mathrm{~kW}$ of installed capacity is the next criteria.

- For dam HPP, reservoir can be delineated. Using spatial intersection of reservoir GISlayer and layers such as agricultural lands, roads, forests and other flooded objects, reservoir creating costs can be calculated, having statistics of reservoir costs for relative sites. If these costs exceed $30 \%$ of entire HPP investments, this site should be excluded.

- Remaining sites after all culling stages should be analyzed to identify the most promising sites. On this step, economic calculations should be performed. Rough estimations of costs of construction for each site can be obtained having the estimation of volumes of 
dam, length of diversion scheme, costs of units and other equipment. These estimations at the prefeasibility stage of the study are fulfilled only for the purpose of searching feasible sites according to preferable topographical and hydrological conditions. Geotechnical conditions should also be taken into account, but at this stage authors only exclude territories with unsuitable geotechnical conditions for hydropower development. After that, all the sites are treated as equal according to geotechnical conditions. According to obtained technical-and-economic indexes, sites can be filtered to find most feasible ones. The final selection of sites can be performed based on multi-criteria analysis to identify the most promising sites.

Figures showing the results of the main steps are shown on Fig.7 (example of dam small hydropower plants siting).

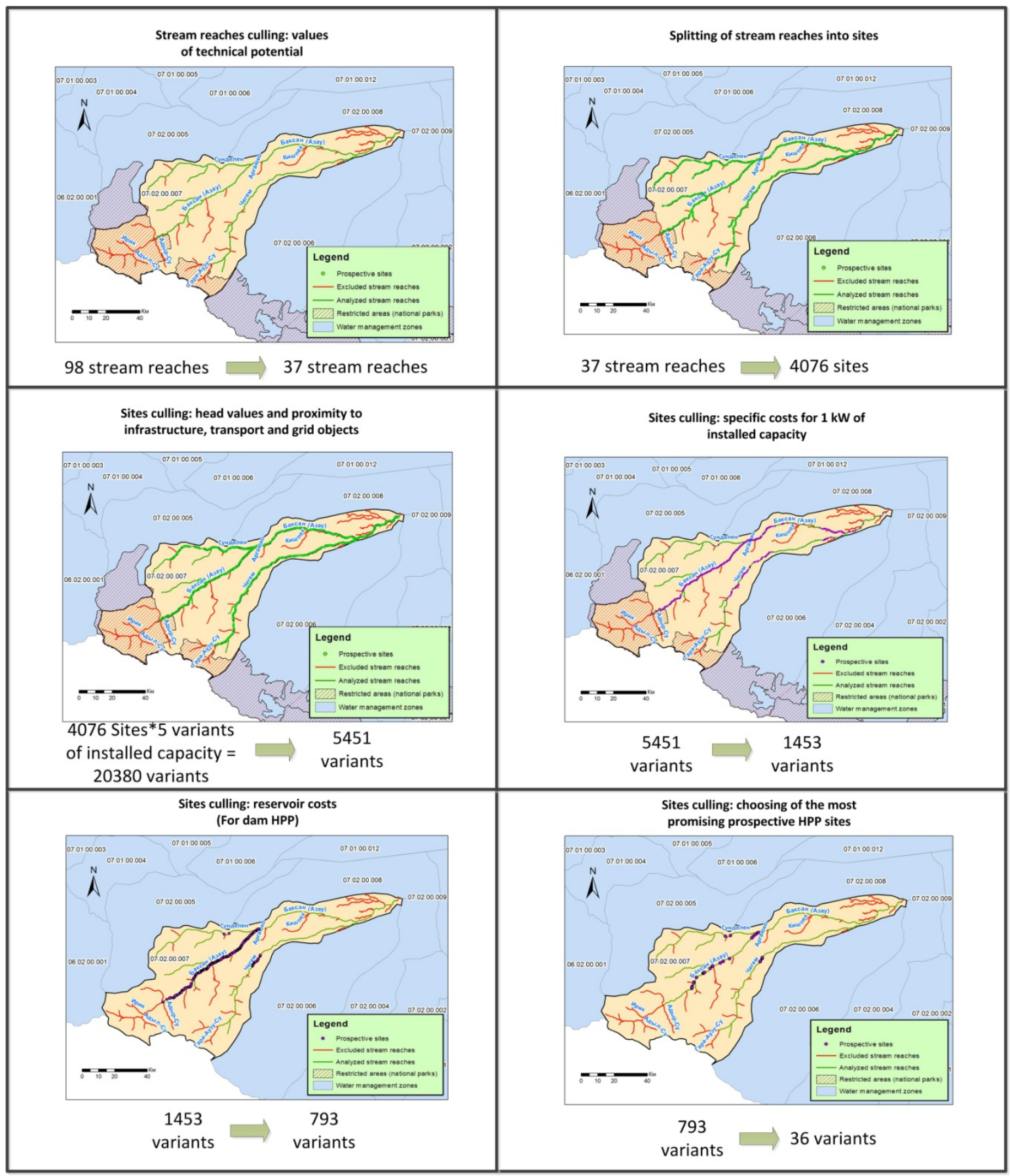

Fig. 7. Results of the main steps of small hydropower plants siting 


\section{CONCLUSION}

Authors have developed and tested methodological approach and GIS-tools for automated hydropower potential estimation. Created GIS-based tools and applications were used for calculation and re-assessment of the hydropower potential in Russia. Verification of obtained results proved their reliability. Currently verification performed for about 300 pour points and 100 gauge stations.

Assessment of hydropower potential can be performed not only for water management areas, but also for administrative regions. Process of calculating hydropower potential is largely automated, so this allows calculating hydropower potential on large areas in a relatively short time. The proposed methodology allowed to execute automated hydropower potential estimation for the territory of Russia. Russian rivers gross hydropower capacity and gross hydropower potential were estimated as $350 \mathrm{GW}$ and $3,07 * 103$ TWh respectively.

Generalized algorithm for identifying prospective hydropower sites is presented in the paper. Figures presenting the results of main steps of the algorithm are shown. Detailed algorithm with criteria used for each factor while comparing the sites will be presented in additional paper, after methodology of feasible sites search is verified and the results are compared with the previous studies.

\section{REFERENCES}

[1] RusHydro: Program of small hydropower development (rus) Available from: http://www.rushydro.ru/industry/res/tidal/ (Accessed on 15.04.2013
[2] Shestopalov P.V. Why only third part of hydropower potential of Northern Caucasus is used? // Energopolis, July August 2012, pp.36-37 (rus). Available from: http://energypolis.ru/portal/2012/1484-pochemugidroyenergeticheskij-potencial-severnogo.html (Accessed on 05.09.2013

[3] Grigoriev S.V. Potential water resources of small rivers in USSR. Leningrad, «Gidrometioizdat», 1946. - 115p.

[4] Voznesenskiy A.N. Hydropower resources of USSR. Moscow, «Nauka», 1967. - 598p.

[5] Feldman B.N., Mikhailov L.P., Markanova T.K. Small hydro. Moscow, «Energoizdat», 1989. - 184p

[6] Punys, P., Dumbrauskas, A., Kvaraciejus, A., Vyciene, G. Tools for small hydropower plant resource planning and development: A review of technology and applications // Energies 2011. 4 (9), pp. 1258-1277

[7] Douglas G. Hall, Shane J. Cherry, Kelly S. Reeves, Randy D. Lee, Gregory R. Carroll, Garold L. Sommers, Kristine L. Verdin. Water Energy Resources of the United States with Emphasis on Low Head/Low Power Resources, IDAHO NATIONAL ENGINEERING AND ENVIRONMENTAL LABORATORY, 2004.

[8] Feizizadeh. B., Haslauer, 2012, GIS-based procedures of hydropower potential for Tabriz basin, Iran, GI Forum 2012, Salzburg, Asutria, July 3-6, 2012, pp.492-502.

[9] Dante G. Larentis, Walter Collischonn, Francisco Olivera, Carlos E.M. Tucci. Gis-based procedures for hydropower potential spotting, Energy 35 (2010), pp.4237-4243.

[10] A. Ballance, D. Stephenson, R. A. Chapman and J. Muller. A geographic information systems analysis of hydropower potential in South Africa. Journal of Hydroinformatics 2 (2000), pp.247-254

[11] National Hydrography Dataset (USA). URL:http://nhd.usgs.gov/index.html (Accessed on 30.08.2013)

[12] SRTM 90m Digital Elevation Data. URL: http://srtm.csi.cgiar.org/ (Accessed on 30.08.2013)

[13] Hydropower Sustainability Assessment Protocol, International Hydropower Association, November 2010, 220 p.

[14] Russian water register database (rus). Available from: http://textual.ru/gvr/ (Accessed on 05.09.2013)

[15] Dean Djokic, Comprehensive Terrain Preprocessing Using Arc Hydro Tools. ESRI, 2008.

[16] GIS-service of Federal State Budgetary Institution "Arctic and Antarctic Research Institute"Available from: http://www.aari.nw.ru/main.php?lg=1 (Accessed on 26.09.2013).

[17] Badenko N.V., Ivanov T.S., Oleshko V.A., GIS methods for searching of feasible HPP sites // Magazine of civil engineering . 2013. №4(39). pp. 70-82. 